\title{
The Effect of Social Media on the Breast Cancer Knowledge and Health Beliefs of Women
}

\author{
Melike Demir Dogan ${ }^{1, *}$, Ebru Karamanli², Hediye Simsek ${ }^{3}$, Tugce Polat ${ }^{4}$, \\ Muhammed Mucahit Yilmaz \\ ${ }^{1}$ Department of Nursing, Faculty of Health Sciences, Gumushane University, \\ Gumushane, Turkey \\ 2 Adana City Hospital, Adana, Turkey \\ 3 Beysehir State Hospital, Beysehir, Turkey \\ 4 Sivas Numune Hospital, Sivas, Turkey \\ 5 Istanbul Basaksehir City Hospital, Istanbul Turkey \\ *Corresponding author: Melike Demir Dogan, Associate Professor, Faculty \\ of Health Sciences, Gumushane University, Baglarbasi Mahallesi 29100, \\ Gumushane, Turkey. Tel: +905334828957; Fax: +904562331179; E-mail: \\ melekdm@gmail.com
}

DOI: $10.30699 /$ mci.5.1.466-1

Submitted: 14 October 2020

Revised: 7 November 2020

Accepted: 18 November 2020

e-Published: 1 December 2020

\section{Keywords:}

Breast Neoplasms

Social Media

Knowledge
Introduction: The present study aimed at determining the effect of social media on breast cancer knowledge and health behaviors of the women.

Methods: The data were collected from 476 women who had willing to participate in the study, using Google forms on social media from February to May 2018.

Results: The results indicated that the time spent on social media decreased, and selfefficacy and health motivation increased by age. The total scores of health beliefs in the subjects believing that social media raised their awareness of breast cancer were higher compared to the ones who did not. The results also showed that the perceived benefit and self-efficacy levels of the subjects increased, and their perceived barrier levels decreased as their breast cancer knowledge increased.

Conclusions: It was concluded that the total scores of health belief of the subjects believing in the role of social media in raising awareness about breast cancer were high, and as their knowledge of breast cancer increased, their perceived benefit and selfefficacy levels increased, and their perceived barrier levels decreased.

(C) 2021. Multidisciplinary Cancer Investigation

\section{INTRODUCTION}

Cancer is one of the major health problems as it is the second leading cause of death after cardiovascular diseases in Turkey and the world [1]. Among all cancer types, breast cancer is the first among the top ten ones observed in women, with a prevalence of $24.2 \%$ [2]. Likewise, it is ranked as the first in Turkey among the top ten cancer types, with a prevalence of $24.8 \%$ in women [3]. The World Health Organization actualized the action plans against the avoidable main risk factors of cancer and recommends early diagnosis and screening programs to prevent cancer [4]. Therefore, the prevention and screening methods to avoid the disease are at the forefront of the fight against cancer in recent years [5]. However, the participation level of women in breast cancer screenings is quite low, although the early diagnosis and screening services are available and free of charge within the scope of the National Cancer Screening Program [6]. Awareness and knowledge levels are important factors in participation in the screenings for early 
diagnosis. Many public service ads are prepared in order to raise awareness in preventing cancer and early diagnosis studies and these are shared in printed and visual media and social media. The recent advances in information technology and access opened a new window to the dissemination of health information. Today, social media are also included in the techniques used in disseminating the preventive health campaigns, such as radio, television, and printed media (i e, posters, brochures, journals) $[7,8]$. As social media is a communication channel sending messages, it provides easy and cost-effective opportunities for users to prepare, share, and receive digital content as text, image, video, and audio, and comment on the contents [9]. Today, more than $85 \%$ of Americans use the Internet regularly, and almost half of them use at least one social media site (i.e, Facebook, Twitter), and the number of individuals using social media increases rapidly [10]. Therefore, social media platforms with billions of active users provide valuable opportunities to increase the participation of people in various health, sciences, and other social topics [11]. In the digital era, individuals and institutions produce and disseminate high amounts of information about cancer in social media. This extensive information may reach the masses through social media and, in turn, may shape the collective and individual beliefs in cancer $[12,13]$. Thus, as a result of a systematic review, the health information presented in social media gives hope to promote health [14]. Nonprofit organizations and state health institutions increasingly use social media sites to get access to people [15].

Social media are utilized to promote behavioral changes and improve health outcomes [14, 16, 17]. In light of this information, the present study aimed at determining the effect of social media on the knowledge of breast cancer and health behaviors in women aged above 18 .

\section{METHODS}

\section{Study Design and Participants}

The present cross sectional study was performed on 476 individuals willing to participate in the study using Google forms on social media (i.e, Facebook, WhatsApp) from February to May
2018. The inclusion criteria were: being a woman, age above 18, and using social media. The exclusion criterion was: not meeting the inclusion criteria.

\section{Measures and Instruments}

The data were collected using demographic information form, the comprehensive breast cancer knowledge test, and the Champion health belief model scale. The Comprehensive Breast Cancer Knowledge Test (CBCKT): The instrument was developed by Stager in 1993 [18]. It is a 20-item, truefalse scale, including 8 true and 12 false statements [18]. There are two subscales in CBCKT: general knowledge and curability. However, factor analysis was not performed in the original version of the test to determine the subscales [18]. The reliability and validity of the Turkish version was assessed by Basak in 2015 [19]. The Champion Health Belief Model Scale (CHBMS): The CHBMS was designed by Champion, based on the health belief model in 1984 to measure the beliefs in breast cancer, breast self-examination, and mammography. The reliability and validity of the Turkish version were assessed by Gozum and Aydin. The internal consistency reliability coefficient of the scale varies between 0.69 and 0.83 . In terms of scoring, "strongly disagree" is scored 1, "disagree" 2, "neutral" 3, "agree" 4, and "strongly agree" 5. Higher scores signify that sensitivity and caring increase, and benefits for perceived benefits, barriers for the perceived barrier, health motivation for health motivation, and selfefficacy for self-efficacy are high [20]. In the present study, the breast self-examination dimension of the "health belief scale on breast cancer and screenings" was used.

\section{Statistical Analysis}

Descriptive statistics, means, median, frequencies, and percentages were used to express the sociodemographic characteristics of the study subjects. Comparisons were made using t-test and the Pearson and Spearman correlation coefficients for all statistical analyses, and a two-tailed P-value of less than 0.05 was considered as the level of significance.

\section{RESULTS}

According to the obtained results, the mean age of the participants was $25.96 \pm 8.44$ years, and $33.0 \%$ were married (Table 1). 


\begin{tabular}{lcc}
\hline \multicolumn{2}{l}{ Table 1: Personal Characteristics } & \\
\hline \multicolumn{1}{l}{ Number } & Percentage \\
\hline Marital Status & & \\
Married & 157 & 33.0 \\
Single & 319 & 67.0 \\
Profession & & \\
Student & 246 & 51.7 \\
Officer & 54 & 11.3 \\
Worker & 30 & 6.3 \\
Retired & 3 & 0.6 \\
Private Sector & 12 & 2.5 \\
Unemployed/Jobless & 131 & 27.5 \\
\hline
\end{tabular}

In addition, $40.3 \%$ of the participants stated that they spent three or more hours on social media. Assessing the intended purpose of using social media, a great majority of the participants $(73.1 \%)$ used social media for sharing information, photos, and videos, and communication. Besides, $67.2 \%$ of the participants stated that spending much time on social media affected their health negatively; $57.6 \%$ also reported that the stories sharing on cancer in social media were about breast cancer and $27.5 \%$ stated that they were related to lung cancer. The participants noted that their interest in sharing stories about entertainment (50.6\%) and health (90.1\%) helped them obtain information. Asking where the information about breast cancer could be found, $27.3 \%$ of the participants answered on social media (Table 2).

Table 2: Features of Using Social Media

\begin{tabular}{|c|c|c|}
\hline & Number & Percentage \\
\hline \multicolumn{3}{|c|}{ Daily Time on Social Media, min } \\
\hline 20-30 & 81 & 17.0 \\
\hline $60-120$ & 203 & 42.6 \\
\hline$\geq 180$ & 192 & 40.3 \\
\hline
\end{tabular}

The Usage Purpose of Social Media

$\begin{array}{lrr}\text { Contact } & 71 & 14.9 \\ \text { Sharing Photos, Videos, Music } & 33 & 6.9 \\ \text { Sharing Information } & 24 & 5.0 \\ \text { All } & 348 & 73.1\end{array}$

The Impact of Social Media on Health

\begin{tabular}{|lcr|}
\hline Positive effect & 320 & 67.2 \\
\hline Negative effect & 156 & 32.8 \\
\hline Which Posts Are Your Favorite on Social Media? & \\
\hline Entertainment & 241 & 50.6 \\
\hline Health & 104 & 21.8 \\
\hline
\end{tabular}

\begin{tabular}{|lcc|}
\hline Education & 89 & 18.7 \\
\hline Advertisement & 1 & 0.2 \\
\hline News & 2 & 0.4 \\
\hline Science & 1 & 0.2 \\
\hline Recipes & 8 & 1.7 \\
\hline Religious Tips & 2 & 0.4 \\
\hline Art & 5 & 1.1 \\
\hline All & 23 & 4.8 \\
\hline
\end{tabular}

Which Cancer-Related Posts Do You See Most Frequently on Social Media?

\begin{tabular}{|lrc|}
\hline Lung Cancer & 131 & 27.5 \\
\hline Breast Cancer & 274 & 57.6 \\
\hline Prostate Cancer & 6 & 1.3 \\
\hline Gastric Cancer & 15 & 3.2 \\
\hline Uterine Cancer & 23 & 4.8 \\
\hline Leukemia & 10 & 2.1 \\
\hline Skin Cancer & 1 & 0.2 \\
\hline Laryngeal Cancer & 1 & 0.2 \\
\hline Liver Cancer & 1 & 0.2 \\
\hline Brain Cancer & 2 & 0.4 \\
\hline Lymphoma & 1 & 0.2 \\
\hline All & 3 & 0.6 \\
\hline None & 8 & 1.7 \\
\hline
\end{tabular}

Where Did You Learn What You Know About Breast Cancer?

$\begin{array}{lrr}\text { Schoolbooks } & 116 & 24.4 \\ \text { Training Seminars } & 79 & 16.6 \\ \text { TV, Radio } & 70 & 14.7 \\ \text { Relatives, Friends } & 70 & 14.7 \\ \text { Social Media } & 130 & 27.3 \\ \text { Health Personnel } & 4 & 0.8 \\ \text { Hospital Pamphlets } & 1 & 0.2 \\ \text { All } & 6 & 1.3\end{array}$

Do Social Media Posts About Health Help You Get Information?

\begin{tabular}{lrr} 
Yes & 429 & 90.1 \\
No & 47 & 9.9 \\
\hline
\end{tabular}

As a result of the statistical analysis, a significant correlation was observed between marital status and the health motivation subscale of the health belief model scale, and the married subjects had higher levels of health motivation compared to the single ones $(\mathrm{P}=0.033)$. It was observed that the perceived sensitivity mean scores of the health belief model scale of the subjects stating that social media affected health negatively were higher compared to the ones noted that it did not $(\mathrm{P}=0.002)$. The health belief model scale total scores of the participants 
stating that social media raised awareness of breast cancer were higher compared to those of the ones who noted it did not $(\mathrm{P}=0.027)$. According to the obtained results, as time spent on social media decreased $(\mathrm{r}=-0.241 ; \mathrm{P}<0.001)$, the self-efficacy mean scores of the health belief model scale increased $(\mathrm{r}=0.185 ; \mathrm{P}<0.001)$, and the mean scores of the health motivation subscale of the health belief model scale increased $(\mathrm{r}=0.128 ; \mathrm{P}=0.005)$ by age. As the time spent on social media increased, the mean score of the perceived sensitivity subscale of the health belief model scale $(r=0.091 ; \mathrm{P}=0.048)$, the mean score of the perceived benefit of the health belief model scale $(\mathrm{r}=-0.121 ; \mathrm{P}=0.008)$, the mean score of the health motivation of the health belief model scale $(\mathrm{r}=-0.138 ; \mathrm{P}=0.003)$, and the mean score of the self-efficacy subscale of the health belief model scale decreased $(\mathrm{r}=-0.101 ; \mathrm{P}=0.027)$ (Table 3 ). According to the obtained results, as the breast cancer knowledge of participants increased, the mean score of the perceived benefit subscale of the health belief model scale $(r=0.204 ; \mathrm{P}<0.001)$ and the mean score of the self-efficacy subscale of the health belief model scale increased $(\mathrm{r}=0.125 ; \mathrm{P}=0.006)$, and the mean score of the perceived barrier subscale of the health belief model scale decreased $(\mathrm{r}=-0.158$; $\mathrm{P}=0.001$ ) (Table 3).

\section{DISCUSSION}

As the evidence demonstrating the efficacy of social media in reaching the masses increases, it becomes a method to promote health. Social media platforms provide a way to disseminate health information rapidly and within a wide area, train the public and promote a healthy behavior [17]. Social media, due to its interactive and relational nature, provides an opportunity for individuals to communicate with larger masses and reach them in order to discuss a piece of health problems [21]. Similar to the other parts of the world, the application of social media has also increased rapidly in Turkey. In the current study, $40.3 \%$ of the participants stated spending three or more hours daily on social media. Examining the intended purpose of using social media, a great majority of the participants noted for sharing information, photos, and videos, and communicate. The participants stated that they were interested in sharing mainly for entertainment $(50.6 \%)$ on social media, and sharing health data (90.1\%) helped them obtaining information (90.1\%). Asking the information source of breast cancer, $27.3 \%$ of the participants noted social media. Similarly, asking the information sources of breast cancer from women in a study, the subjects reported mostly from the Internet, television, schoolbooks, and magazines [22]. In light of these results, it may be considered that social media is effective in informing the public about health.

The results of studies indicated that knowledge, attitude, and motivation are the major personal determinants of health behavior. Also, many social, cultural, and economic factors contribute to developing, sustaining, and changing health behavior patterns [23]. The present study showed that as the breast cancer knowledge increased, the perceived benefit and self-efficacy subscale mean scores of the health belief model scale increased, and the perceived barrier subscale mean score decreased. It was observed that increasing the knowledge of breast cancer may be effective in terms of the early diagnosis of the disease. As a matter of fact, it was also stated in the study that the programs performed

Table 3: The Relationship Between the Health Belief Model and Other Variables a

\begin{tabular}{|c|c|c|c|c|c|c|}
\hline & \multicolumn{2}{|c|}{ Age } & \multicolumn{2}{|c|}{ Daily Time Spent on Social Media } & \multicolumn{2}{|c|}{ CBCKT Total Score } \\
\hline & R Value & P Value & R Value & P Value & R Value & PValue \\
\hline CHBMS Total Score & 0.142 & 0.002 & -0.046 & 0.313 & 0.058 & 0.209 \\
\hline Sensitivity & -0.027 & 0.557 & 0.091 & 0.048 & 0.029 & 0.521 \\
\hline Seriousness & -0.030 & 0.507 & 0.086 & 0.062 & -0.077 & 0.092 \\
\hline Health Motivation & 0.128 & 0.005 & -0.122 & 0.008 & 0.105 & 0.022 \\
\hline BSE Related Barriers & 0.012 & 0.790 & 0.046 & 0.320 & -0.158 & 0.001 \\
\hline Benefits Regarding BSE & 0.044 & 0.336 & -0.110 & 0.017 & 0.204 & $\mathrm{P}<0.001$ \\
\hline BSE Self-Effectiveness & 0.185 & $\mathrm{P}<0.001$ & -0.089 & 0.052 & 0.125 & 0.006 \\
\hline
\end{tabular}

a Abbreviations: BSE, breast self examination; CBCKT, the comprehensive breast cancer knowledge test; CHBMS, the Champion health belief model scale 
on the correlation between abdominal obesity and cancer in Australia increased awareness of the audiences [24]. A study examining the effect of social media shares on breast cancer and smoking attitudes in young people reported that young people learned from a video sharing that smoking increases the risk of breast cancer, and they should avoid smoking to protect themselves [25]. It was also observed in the present study that the health belief model scale total scores of the participants believing that social media raised awareness of breast cancer were higher compared to those of the ones that did not. It was shown that as the time spent on social media increased, the sensitivity perceived subscale mean score of the health belief model scale increased, and the mean scores of perceived benefit, health motivation and self-efficacy subscales decreased. Therefore, it may be considered that social media shares are effective in obtaining knowledge and increasing sensitivity to go into action. However, it had a negative impact in terms of the perceived benefit, self-efficacy, and health motivation. The mean age of the study subjects was $25.96 \pm 8.44$ years. The study participants belonged to a certain age range; $9.1 \%$ to the age range of 65 and above and $15.6 \%$ to the age group of 15-24 years [26]. Social media is used by the latter group in Turkey, and it is quite expectable that the elderly constitute the minority.

It was observed that social media was effective in increasing the knowledge of breast cancer and as knowledge increases, the awareness also increases. It is recommended to thoroughly investigate the effect of the content of the shared information and the effect of social media on the elements, such as health motivation and self-efficacy, in future studies. The use of certain social media platforms in order to include only the social media users might limit the sample to a certain age range. For generalizing the obtained results of the study to the whole population in Turkey, it is recommended to perform further studies with larger sample sizes, including all age groups.

\section{ACKNOWLEDGMENTS}

None.

\section{CONFLICT OF INTEREST}

The authors declared no conflict of interest.

\section{ETHICS APPROVAL}

The study protocol was approved by the Scientific Research and Publication Ethics Committee of Gumushane University.

\section{REFERENCES}

1. Forman D, Ferlay C. The global and regional burden of cancer. In: Stewart BW, Wild CP, editors. World Cancer Report 2014. 1st ed. Lyon, France: International Agency for Cancer Reports (IACR) Publications; 2014. p. 16-53.

2. Ferlay J, Ervik M, Lam F, Colombet M, Mery L, Pineros $\mathrm{M}$, et al. Global Cancer Observatory: Cancer Today. Lyon, France International Agency for Research on Cancer; 2018 [updated 2018 Sep; cited 2020]. Available from: https://gco. iarc.fr/today/home.

3. Bora Basara B, Soytutan Caglar I, Aygun A, Ozdemir TA. [Health Statistics Yearbook 2018]. Ankara, Turkey: Republic of Turkey, Ministry of Health, General Directorate of Health Information Systems; 2019.

4. Cancer Department. [Cancer Screening]. Ankara, Turkey: Republic of Turkey, Ministry of Health, General Directorate of Public Health; 2020 [updated 2018 Jan 16; cited 2018 Jan 16]. Available from: https://hsgm.saglik.gov.tr/tr/kanser-taramalari.

5. Kanbur A, Capık Y. [Cervical Cancer Prevention, Early Diagnosis-Screening Methods and Midwives / Nurses Role]. J Hacettepe Univ Fac Nurs. 2011;18(1):61-72.

6. Kolutek R, Avci IA. The Effect of Training and Monitoring at Home on the Knowledge Level and Practices of Married Women Regarding Breast and Cervical Cancer. J Breast Health. 2015;11(4):155-62. DOI: 10.5152/tjbh.2015.2647 PMID: 28331714.

7. Fox S. Health Topics: $80 \%$ of Internet Users Look for Health Information Online. 2011 [cited 2020 Nov 19]. Available from: https://www.issuelab.org/resource/health-topics-80of-internet-users-look-for-health-information-online.html.

8. Koch-Weser S, Bradshaw YS, Gualtieri L, Gallagher SS. The Internet as a health information source: findings from the 2007 Health Information National Trends Survey and implications for health communication. J Health Commun. 2010;15 Suppl 3:279-93. DOI: 10.1080/10810730.2010.522700 PMID: 21154099.

9. Moorhead SA, Hazlett DE, Harrison L, Carroll JK, Irwin A, Hoving C. A new dimension of health care: systematic review of the uses, benefits, and limitations of social media for health communication. J Med Internet Res. 2013;15(4):e85. DOI: 10.2196/jmir.1933 PMID: 23615206.

10. Duggan M, Ellison NB, Lampe C, Lenhart A, Madden M, Rainie L, et al. Social Media Update 2014. Washington, D.C., USA: Pew Research Center; 2015 [updated Jan 9]. Available from: https://www.pewresearch.org/internet/2015/01/09/social-media-update-2014/.

11. Social Media Fact Sheet. Washington, D.C., USA: Pew Research Center; 2019 [updated 2019 Jun 12]. Available from: https://www.pewresearch.org/internet/fact-sheet/social-media/. 
12. Chen L, Wang X, Peng TQ. Nature and Diffusion of Gynecologic Cancer-Related Misinformation on Social Media: Analysis of Tweets. J Med Internet Res. 2018;20(10):e11515. DOI: 10.2196/11515 PMID: 30327289.

13. Xu S, Markson C, Costello KL, Xing CY, Demissie K, Llanos AA. Leveraging Social Media to Promote Public Health Knowledge: Example of Cancer Awareness via Twitter. JMIR Public Health Surveill. 2016;2(1):e17. DOI: 10.2196/ publichealth.5205 PMID: 27227152.

14. Maher CA, Lewis LK, Ferrar K, Marshall S, De Bourdeaudhuij I, Vandelanotte $\mathrm{C}$. Are health behavior change interventions that use online social networks effective? A systematic review. J Med Internet Res. 2014;16(2):e40. DOI: 10.2196/ jmir.2952 PMID: 24550083.

15. Thackeray R, Keller H, Heilbronner JM, Dellinger LK. Social marketing's unique contribution to mental health stigma reduction and HIV testing: two case studies. Health Promot Pract. 2011;12(2):172-7. DOI: 10.1177/1524839910394176 PMID: 21427270 .

16. Nakhasi A, Shen AX, Passarella RJ, Appel LJ, Anderson CA. Online social networks that connect users to physical activity partners: a review and descriptive analysis. J Med Internet Res. 2014;16(6):e153. DOI: 10.2196/jmir.2674 PMID: 24936569.

17. Korda H, Itani Z. Harnessing social media for health promotion and behavior change. Health Promot Pract. 2013;14(1):15-23. DOI: 10.1177/1524839911405850 PMID: 21558472.

18. Stager JL. The comprehensive Breast Cancer Knowledge Test: validity and reliability. J Adv Nurs. 1993;18(7):1133-40. DOI: 10.1046/j.1365-2648.1993.18071133.x PMID: 8370905.

19. Basak SC. [Breast cancer knowledge level of university stu- dents: validity and reliability study of a large breast cancer knowledge test]. [Istanbul, Turkey]: Okan University. Social Sciences Institute; 2015. 53 p.

20. Gozum S, Aydin I. Validation evidence for Turkish adaptation of Champion's Health Belief Model Scales. Cancer Nurs. 2004;27(6):491-8. PMID: 15632789.

21. Cobb NK, Poirier J. Effectiveness of a multimodal online well-being intervention: a randomized controlled trial. Am J Prev Med. 2014;46(1):41-8. DOI: 10.1016/j.amepre.2013.08.018 PMID: 24355670.

22. Guzel N, Bayraktar N. [Determination of Women's Awareness and Practices on Early Diagnosis of Breast Cancer]. $\mathrm{J}$ Hacettepe Univ Fac Nurs. 2019;6(2):101-10.

23. Glanz K, Bishop DB. The role of behavioral science theory in development and implementation of public health interventions. Annu Rev Public Health. 2010;31:399-418. DOI: 10.1146/annurev.publhealth.012809.103604 PMID: 20070207.

24. Morley B, Wakefield M, Dunlop S, Hill D. Impact of a mass media campaign linking abdominal obesity and cancer: a natural exposure evaluation. Health Educ Res. 2009;24(6):106979. DOI: 10.1093/her/cyp034 PMID: 19570919.

25. Bottorff JL, Struik LL, Bissell LJ, Graham R, Stevens J, Richardson CG. A social media approach to inform youth about breast cancer and smoking: an exploratory descriptive study. Collegian. 2014;21(2):159-68. DOI: 10.1016/j.colegn.2014.04.002 PMID: 25109215.

26. Turkstat News Bulletins. [Youth in Statistics, 2019]. Ankara, Turkey: Information Distribution Group Presidency; 2020 [updated 2015 May 15; cited 2015 May 15]. Available from: https://data.tuik.gov.tr/Bulten/Index?p=Istatistiklerle-Genclik-2019-33731. 